\title{
Evaluation of the Efficacy and Safety of Laser versus Cold Knife Urethrotomy in the Management of Patients with Urethral Strictures: A Systematic Review and Meta-Analysis of Randomized Clinical Trials
}

\author{
Lynda Torres Castellanos $^{a} \quad$ María Camila Moreno Bencardino $^{a} \quad$ Alejandra Bravo-Balado $^{b}$ \\ Carlos Andrés García Mayorga ${ }^{a} \quad$ Isis Vargas Manrique ${ }^{a} \quad$ Nicolás Fernández $^{\text {a, c, d }}$ \\ a Department of Urology, Hospital Universitario San Ignacio and Pontificia Universidad Javeriana School of Medicine, \\ ${ }^{b}$ Department of Urology, Hospital Universitario Fundación Santa Fe de Bogotá and Universidad de los Andes School of \\ Medicine, and ${ }^{\mathrm{C} H u m a n}$ Genetics Institute, Pontificia Universidad Javeriana, Bogotá D.C., Colombia; ${ }^{\mathrm{d}}$ Division of Urology, \\ Hospital for SickKids, Toronto, ON, Canada
}

\section{Keywords \\ Urethra - Urethral stricture - Urethral stenosis - Laser . \\ Cold knife - Urethrotomy - Urethral reconstruction . \\ Efficacy · Safety $\cdot$ Recurrence rate}

\begin{abstract}
Introduction: Urethral strictures generate great morbidity. Two procedures have been described for their management - laser and cold knife techniques - which are still widely used. We aim to assess the safety and efficacy of laser versus cold knife urethrotomy. Materials and Methods: We conducted a systematic search of the literature using MEDLINE, EMBASE, LILACS and Cochrane databases and gray literature. Primary outcomes were urethral stricture recurrence, time-to-recurrence and complication rate. Secondary outcomes were quality of life and maximum urinary flow rate (Qmax). Data analysis was obtained using Review Manager 5.2. Results: Out of 137 publications, 4 articles were included in the meta-analysis. At 3 months, the recurrence rate was similar in both groups $(0.55,95 \% \mathrm{Cl} 0.18-1.66)$, but at 6 and 12 months, it was significantly lower in the laser urethrotomy group $(0.39,95 \% \mathrm{Cl} 0.19-0.81$ and $0.44,95 \% \mathrm{Cl} 0.26-0.75)$.
\end{abstract}

The analysis of Qmax at 6 months post-intervention suggested a greater improvement in the laser urethrotomy group. A qualitative analysis showed that complications in both procedures were minor and infrequent. Conclusions: Laser urethrotomy has a lower recurrence rate at 6 and 12 months compared to cold knife urethrotomy. Complications in both procedures are minor and infrequent. Results should be interpreted cautiously, since they were evaluated only for a short term.

๑) 2017 S. Karger AG, Basel

\section{Background}

Urethral stricture is one of the oldest urological entities reported in the literature, with treatments described since $600 \mathrm{BC}$ [1]. Its prevalence in developed countries is estimated to be $0.6 \%$ and is thought to be higher in undeveloped countries [2].

A vast majority of urethral strictures are secondary to surgical instrumentation. For instance, the prevalence of a stricture following transurethral resection of the prostate ranges between 3 and 5\% [3]. Other reported

\section{KARGER}

(c) 2017 S. Karger AG, Basel

E-Mail karger@karger.com

www.karger.com/uin
Lynda Torres Castellanos, MD

Department of Urology, Hospital Universitario San Ignacio and Pontificia Universidad Javeriana, Carrera 7 No. 40-62, Unidad de Urología, Piso 8, Bogotá DC 110111 (Colombia)

E-Mail lynda_torres@javeriana.edu.co 
etiologies are urethritis and failed hypospadias repair [4].

Urethral stricture is a prevalent condition associated with great morbidity. It can cause obstructive urinary symptoms, which depending on the severity and the degree of the stricture, can be severe, jeopardizing the patient's quality of life (QoL) and leading to obstructive uropathy, urinary tract infection and renal disease [5].

Internal urethrotomy is a commonly used procedure for treating urethral strictures, especially in undeveloped countries. Nonetheless, strong evidence capable of generating a recommendation based on the postoperative outcomes and complications of the laser urethrotomy versus the cold knife urethrotomy is lacking. Therefore, our aim was to compare the efficacy and safety of both techniques in patients with urethral stricture according to the best available evidence.

\section{Methods}

Protocol

A research protocol was developed by the authors and approved by the Ethics Committee of our institution in May 2016.

\section{Search Strategy}

In May 2016, using the terms "urethral stenosis," "urethral stricture," "urethrotomy," "laser," and "cold knife," a systematic search of the literature with no time limit was performed in MEDLINE, EMBASE, LILACS, Cochrane, GreyNet, and OpenGrey databases.

The identified articles were independently reviewed by 2 authors according to the Consolidated Standards of Reporting Trials (CONSORT) [6]. We used the Preferred Reporting Items for Systematic Review and Meta-Analysis (PRISMA) statement, checklist and flow diagram. Also, the methodology of non-formal consensus including the opinion of a third author was used when disagreements were encountered.

\section{Inclusion Criteria}

Randomized controlled trials (RCTs) comparing both laser and cold knife urethrotomy in human subjects were included.

\section{Exclusion Criteria}

Animal studies, studies in patients with lower urinary tract symptoms not explained by urethral stricture or studies where other procedures different from urethrotomy were performed (i.e., urethroplasty) were excluded.

\section{Primary Outcomes}

The primary outcome for efficacy was stricture recurrence. For safety, the primary outcome was the occurrence of complications. The secondary outcomes evaluated were maximum urinary flow rate (Qmax) and QoL.

\section{Data Extraction}

Using a standardized format, information about the study was extracted, including study design, risk of bias, epidemiologic char- acteristics of the participants, type of intervention, etiology and location of the stricture, follow-up duration, recurrence rate, complications, QoL and Qmax.

\section{Summary Measures and Statistical Analysis}

Treatment effect was measured using risk ratio (RR) for dichotomous outcomes. For qualitative variables, weighted mean difference was used. A 95\% CI was used in every case. When at least 2 studies were available for the same outcome, a heterogeneity analysis was made with a visual exploration of the forest plot and the heterogeneity $\left(I^{2}\right)$ estimate. Statistical analysis was conducted with Review Manager 5.2 using fixed-effects models.

\section{Risk of Bias in Individual Studies}

For each study, the assessment of risk of bias was conducted using the Cochrane instrument for assessing the risk of bias; 7 domains were included: random sequence generation, allocation concealment, blinding of participants and personnel, blinding of outcome assessment, incomplete outcome data, selective reporting and other bias. For each domain, the risk of bias was determined to be high, low, or not clear.

\section{Results}

\section{Study Selection}

A total of 137 articles were found in the initial search, out of which 83 were found in MEDLINE, 35 in EMBASE, 18 in LILACS, and 1 in Cochrane databases. No results were found in the gray literature. Two authors reviewed the publications' titles and abstracts and selected those that fulfilled the inclusion criteria. They were analyzed with the CONSORT instrument to include those with an RCT design. After applying this instrument, 4 studies were finally selected, whose authors were Atak et al. [7], Jain et al. [8], Jabłonowski et al. [9] and Dutkiewicz and Wroblewski [10] (Fig. 1).

\section{Studies Characteristics}

The present review focused exclusively on RCTs. Included studies had 2 intervention groups: the laser urethrotomy and the cold knife urethrotomy. A summary of the studies characteristics is provided in Table 1.

\section{Assessment of Risk of Bias}

Table 2 shows the risk of bias in individual studies using the 7 domains previously mentioned.

\section{Synthesis of Results}

Recurrence rate

Recurrence rate at 3, 6, and 12 months was evaluated in Atak et al. [7] and Jabłonowski et al. [9] studies, which had similar outcomes. 
Fig. 1. Systematic review flow diagram.

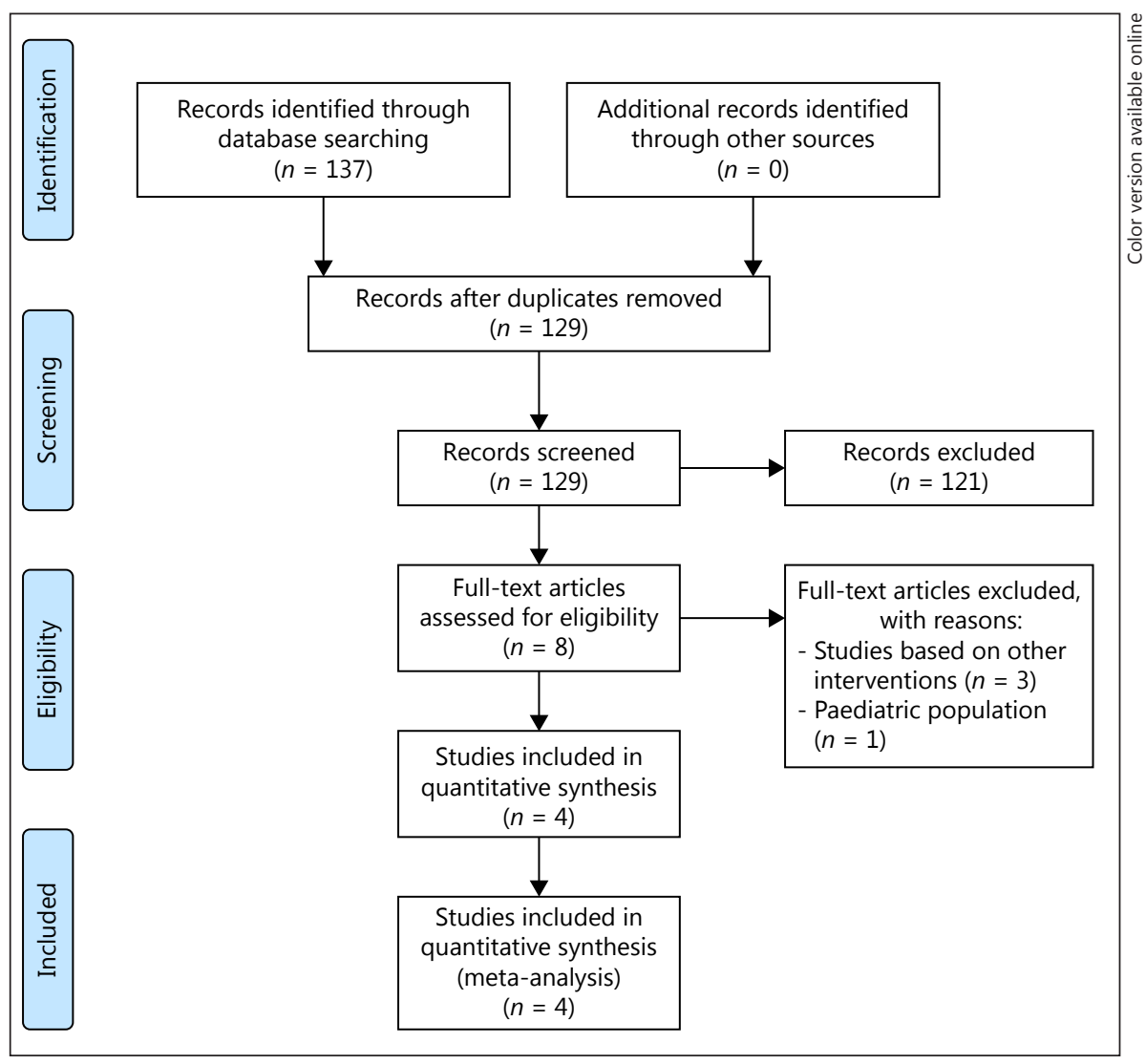

At 3 months, the RR for recurrence was 0.55 (95\% CI $0.18-1.66, p=0.29$ ), which favored the laser urethrotomy. However, these results were not statistically significant (Fig. 2).

At 6 and 12 months, the analysis showed an RR of 0.39 (95\% CI $0.19-0.81, p=0.01)$ and an RR of 0.44 (95\% CI $0.26-0.75, p=0.003)$, respectively, which favored the laser urethrotomy group (Fig. 3, 4).

\section{Complications}

Neither Atak et al. [7] and Jabłonowski et al. [9] nor Dutkiewicz and Wroblewski [10] reported complications during or after the procedure.

Jain et al. [8] reported a $12.2 \%$ overall complication rate. In the laser group, an $8.9 \%$ rate was found due to contrast extravasation to the perineum and stricture recurrence. For the cold knife group, a 15.5\% was found due to bleeding.

\section{Quality of Life}

Jabłonowski et al. [9] evaluated the International Prostate Severity Score and applied a QoL questionnaire before and after the procedure. No statistically significant differences were found between both interventions.

Dutkiewicz and Wroblewski [10] evaluated QoL before and after the procedure and at 12-month follow-up. They found no statistically significant differences.

\section{Maximum Urinary Flow Rate}

For this outcome, the results of studies conducted by Dutkiewicz and Wroblewski [10] and Jain et al. [8] at 6 months were compared. The analysis showed a weighted mean difference of -3.33 (95\% CI -4.76 to -1.90 , $p<$ 0.0001 ), demonstrating a higher mean of maximum flow rate in the laser urethrotomy (Fig. 5).

\section{Discussion and Limitations}

In the United States, in 2001, the admission rate to the emergency department for symptoms secondary to urethral stricture was 6.9/100,000. According to data of the year 2000, 191 million US dollars were spent towards this condition [2]. In undeveloped countries, where the prevalence of the disease is greater, a higher rate of expendi- 
Table 1. Description of included randomized clinical trials

\begin{tabular}{|c|c|c|c|c|c|c|c|c|c|}
\hline & Study location & $n$ & $\begin{array}{l}\text { Age, years, } \\
\text { mean } \\
\text { (range) }\end{array}$ & Etiology of stricture & Localization of stricture & Intervention & $\begin{array}{l}\text { Follow-up, } \\
\text { months }\end{array}$ & $\begin{array}{l}\text { Recurrence } \\
\text { rate ( } 12 \\
\text { months) }\end{array}$ & $\begin{array}{l}\text { Main } \\
\text { complications }\end{array}$ \\
\hline $\begin{array}{l}\text { Atak et al. [7], } \\
2011\end{array}$ & $\begin{array}{l}\text { Zonguldak, } \\
\text { Turkey }\end{array}$ & 51 & $61(24-85)$ & $\begin{array}{l}\text { Iatrogenic }(n=33) \text {, } \\
\text { bladder neck } \\
\text { contracture }(n=18)\end{array}$ & $\begin{array}{l}\text { Bulbar }(n=33) \text {, bladder } \\
\text { neck }(n=8)\end{array}$ & $\begin{array}{l}\text { HO:YAG laser } \\
(n=21), \text { cold } \\
\text { knife }(n=30)\end{array}$ & $\begin{array}{l}1,3,6,9 \\
12\end{array}$ & $\begin{array}{l}\text { Laser } 19.0 \% \text {, } \\
\text { cold knife } \\
46.6 \%\end{array}$ & None \\
\hline $\begin{array}{l}\text { Jabłonowski } \\
\text { et al. [9], } 2010\end{array}$ & Lodz, Poland & 50 & $62(22-83)$ & $\begin{array}{l}\text { Iatrogenic }(n=30), \\
\text { traumatic }(n=5), \\
\text { infectious }(n=1), \\
\text { undetermined }(n=14)\end{array}$ & $\begin{array}{l}\text { Membranous }(n=26) \text {, } \\
\text { penile }(n=12) \text {, bulbar } \\
(n=4), \text { multiple }(n=8)\end{array}$ & $\begin{array}{l}\text { Nd-YAG laser } \\
(n=30), \text { cold } \\
\text { knife }(n=20)\end{array}$ & $3,6,12$ & $\begin{array}{l}\text { Laser } 30 \% \text {, } \\
\text { cold knife } \\
65 \%\end{array}$ & None \\
\hline $\begin{array}{l}\text { Dutkiewicz } \\
\text { and } \\
\text { Wroblewski } \\
{[10], 2012}\end{array}$ & $\begin{array}{l}\text { Katowice, } \\
\text { Poland }\end{array}$ & 50 & $63(17-78)$ & $\begin{array}{l}\text { Iatrogenic }(n=32) \\
\text { idiopathic }(n=18)\end{array}$ & $\begin{array}{l}\text { Bulbar }(n=8), \text { penile } \\
(n=19), \text { membranous } \\
(n=13), \text { prostatic }(n= \\
19)\end{array}$ & $\begin{array}{l}\text { Holmium laser } \\
(n=25), \text { cold } \\
\text { knife }(n=25)\end{array}$ & $3,6,12$ & - & None \\
\hline $\begin{array}{l}\text { Jain et al. [8], } \\
2014\end{array}$ & $\begin{array}{l}\text { New Delhi, } \\
\text { India }\end{array}$ & 90 & $18-60$ & $\begin{array}{l}\text { Inflammatory }(n=42) \text {, } \\
\text { catheterization }(n=29) \text {, } \\
\text { traumatic }(n=10) \text {, } \\
\text { idiopathic }(n=9)\end{array}$ & $\begin{array}{l}\text { Penile }(n=21) \text {, bulbar } \\
(n=22), \\
\text { bulbomembranous }(n= \\
36), \text { posterior }(n=11)\end{array}$ & $\begin{array}{l}\text { Holmium }(n= \\
45), \text { cold knife } \\
(n=24)\end{array}$ & 1,6 & - & $\begin{array}{l}\text { Extravasation } \\
\text { of contrast } \\
\text { agent, bleeding }\end{array}$ \\
\hline
\end{tabular}

Table 2. Risk of bias in individual studies

\begin{tabular}{|c|c|c|c|c|}
\hline & $\begin{array}{l}\text { Atak et al. [7], } \\
2011\end{array}$ & $\begin{array}{l}\text { Jabłonowski et al. } \\
{[9], 2010}\end{array}$ & $\begin{array}{l}\text { Dutkiewicz and } \\
\text { Wroblewski [10], } \\
2012\end{array}$ & $\begin{array}{l}\text { Jain et al. [8], } \\
2014\end{array}$ \\
\hline Random sequence generation & Low risk & Unclear & High risk & Low risk \\
\hline Allocation concealment & Low risk & Unclear & High risk & Unclear \\
\hline Blinding of participants and personnel & High risk & High risk & High risk & High risk \\
\hline Blinding of outcome assessment & Unclear & Unclear & Unclear & Unclear \\
\hline Incomplete outcome data & High risk & High risk & Low risk & Low risk \\
\hline Selective reporting & Unclear & Unclear & Unclear & Unclear \\
\hline Other biases & Unclear & Unclear & Unclear & Unclear \\
\hline
\end{tabular}

ture is estimated [1]. Regarding its management, urethroplasty is the standard of care, with up to $90 \%$ chance of success [11]. In this procedure, a preputial/penile skin flap is considered an excellent material for urethral reconstruction associated with lower incidence of stricture recurrence, especially when patients do not have suitable oral mucosa [12]. Other most commonly used treatment options are urethral dilation and internal urethrotomy [11].

Bullock and Brandes [13] conducted a survey among 431 members of the American Urological Association, and found that $63 \%$ of the urologists treated from 6 to 20 urethral strictures annually, internal urethrotomy being the most commonly used procedure (85.6\%). The authors highlighted that most urologists were not trained in urethroplasty.
In 2016, a survey conducted among the members of the Sociedad Colombiana de Urología showed that 33\% of participants preferred the use of internal urethrotomy as the initial management of urethral strictures. Almost $50 \%$ of them use internal urethrotomy for bulbar urethral strictures. When it comes to strictures localized in the penile urethra, $70 \%$ prefer a minimally invasive management [14].

As previously stated, open urethral reconstruction is the best choice for the management of urethral strictures; however, it requires an adequate medical training and optimal surgical facilities. These conditions are not available in many countries, resulting in the use of alternative methods such as the internal urethrotomy [15].

A study conducted in Nigeria (Ogbonna [16]) showed that both the urethrotomy and the urethral dilation may 


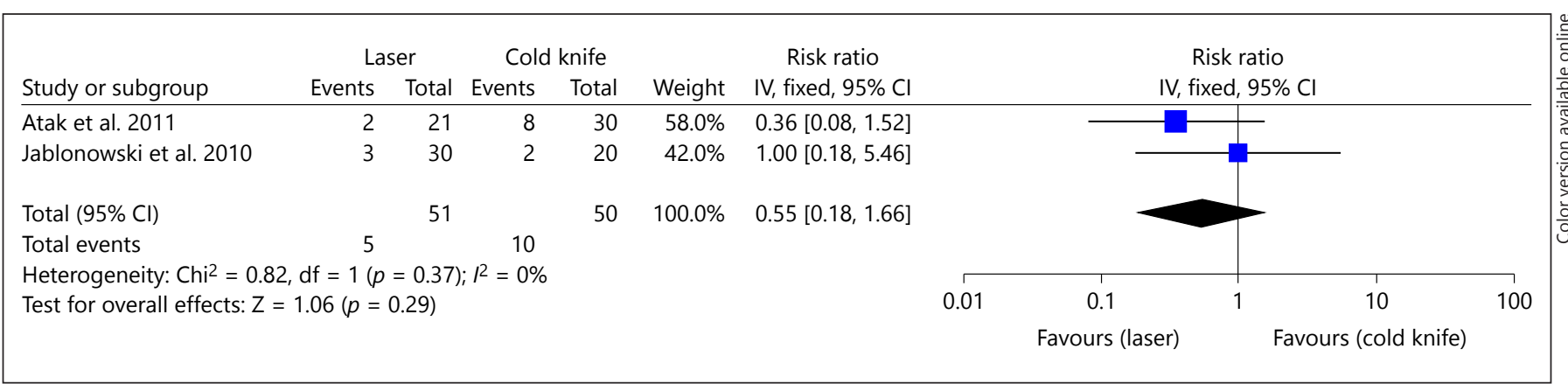

Fig. 2. Forrest plot and meta-analysis of recurrence rate at 3 months.

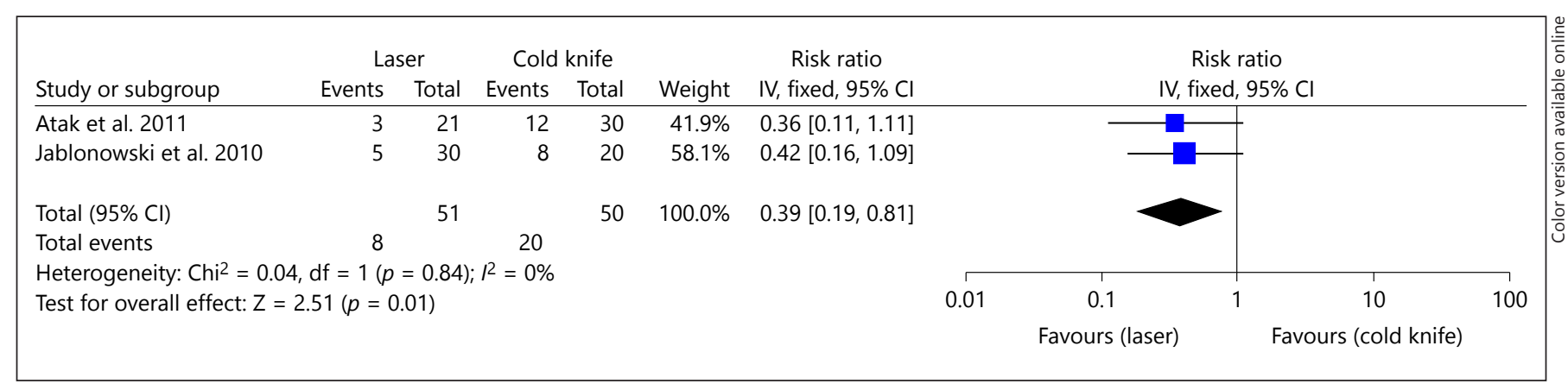

Fig. 3. Forrest plot and meta-analysis of recurrence rate at 6 months.

\begin{tabular}{|c|c|c|c|c|c|c|c|c|c|c|c|}
\hline \multirow[b]{2}{*}{ Study or subgroup } & \multicolumn{2}{|c|}{ Laser } & \multicolumn{2}{|c|}{ Cold knife } & \multirow[b]{2}{*}{ Weight } & \multirow{2}{*}{$\begin{array}{c}\text { Risk ratio } \\
\text { IV, fixed, } 95 \% \mathrm{CI}\end{array}$} & \multirow{2}{*}{\multicolumn{5}{|c|}{$\begin{array}{c}\text { Risk ratio } \\
\text { IV, fixed, } 95 \% \mathrm{CI}\end{array}$}} \\
\hline & Events & Total & Events & Total & & & & & & & \\
\hline Atak et al. 2011 & 4 & 21 & 14 & 30 & $30.3 \%$ & $0.41[0.16,1.07]$ & & & & & \\
\hline Jablonowski et al. 2010 & 9 & 30 & 13 & 20 & $69.7 \%$ & $0.46[0.24,0.87]$ & & & & & \\
\hline Total $(95 \% \mathrm{Cl})$ & & 51 & & 50 & $100.0 \%$ & $0.44[0.26,0.75]$ & & & & & \\
\hline Total events & 13 & & 27 & & & & & & & & \\
\hline \multicolumn{7}{|c|}{ Heterogeneity: $\mathrm{Chi}^{2}=0.04, \mathrm{df}=1(p=0.83) ; I^{2}=0 \%$} & & 1 & & & \\
\hline \multirow{2}{*}{\multicolumn{7}{|c|}{ Test for overall effect: $Z=3.00(p=0.003)$}} & 0.01 & 0.1 & 1 & 10 & 100 \\
\hline & & & & & & & & Favours ( & & (colc & \\
\hline
\end{tabular}

Fig. 4. Forrest plot and meta-analysis of recurrence rate at 12 months.

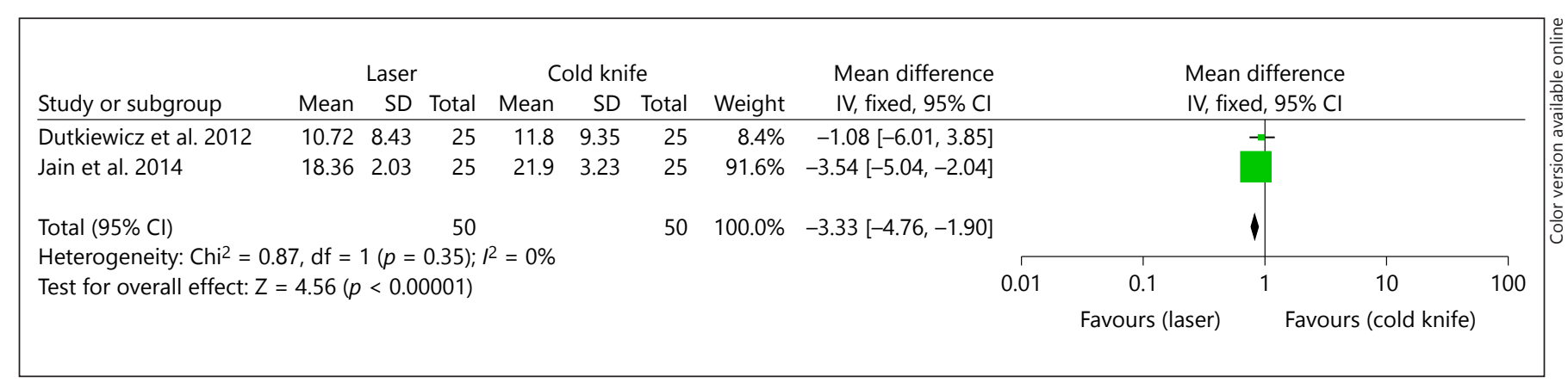

Fig. 5. Forrest plot and meta-analysis of maximum urinary flow rate at 6 months.

Efficacy and Safety of Laser vs. Cold Knife Urethrotomy 
manage up to $75 \%$ of patients with urethral strictures, which was associated with good short-term results. The authors stated that urethrotomy is a low-cost procedure and is 10 times less time consuming than urethroplasty, which is why they propose the former as the leading choice in the initial management of urethral strictures in the absence of trained personnel, adequate facilities or ease of referral to specialized care centres [16].

Greenwell et al. [17] in a study comparing internal urethrotomy versus urethroplasty with specific reference to cost effectiveness concluded that in urethral strictures with less than $60 \%$ chance of recurrence - less than $1 \mathrm{~cm}$ long with little spongiofibrosis - internal urethrotomy is a cost-effective initial treatment measure.

Jin et al. [18] published a meta-analysis in 2010 based on non-comparative observational studies. This study included 44 articles, out of which 19 evaluated laser urethrotomy and 25 evaluated cold knife urethrotomy. Consistent with our results, the authors found a success rate of $74.9 \%$ for the laser urethrotomy compared to $68.5 \%$ for the cold knife urethrotomy group, with a $p$ value of 0.004 . However, they mainly included descriptive studies. Moreover, the follow-up duration among studies was heterogeneous, which did not allow an adequate analysis of the recurrence rate.

Currently, the American Urological Association guidelines in male urethral stricture, with a strength-ofrecommendation $\mathrm{C}$, states that the laser urethrotomy and the cold knife urethrotomy may be used indistinctively [19]. This recommendation was solely based on 2 independent RCTs $[7,20]$.

In this article, we provide the first meta-analysis including only RCTs comparing both techniques. Although at the 3rd-month follow-up the results did not show a statistically significant difference among the aforementioned techniques, at the 6th- and 12th-month follow-up, there was a statistically significant lower recurrence rate for the laser urethrotomy group when compared to the cold knife urethrotomy group.

Regarding complications, none were reported in 3 of the studies included in the meta-analysis and Jain et al. [8] only reported a few, which were all minor in nature.

The results of our study were limited by the shortterm outcome evaluation among the publications included in the meta-analysis. Additionally, these 4 studies did not specify the results based on the location of the stricture.

\section{Conclusions}

Our results may demonstrate that at 6 and 12 months postoperatively, the laser urethrotomy technique offers a lower recurrence rate compared to the cold knife urethrotomy. Complications with any of these techniques were minor and infrequent. These results should be interpreted cautiously, since they were evaluated at short term. Further investigations using well-designed randomized clinical trials are needed in order to achieve the best management of urethral strictures based on where they are located.

\section{Disclosure Statement}

The authors have no commercial or financial incentive associated with the writing and publishing of this work.

\section{References}

1 Brandes SB, Morey AF: Advanced Male Urethral and Genital Reconstructive Surgery. New York, Springer New York, 2014.

2 Santucci RA, Joyce GF, Wise M: Male urethral stricture disease. J Urol 2007;177:16671674.

3 Tritschler S, Roosen A, Füllhase C, Stief CG, Rübben H: Urethral stricture: etiology, investigation and treatments. Dtsch Arztebl Int 2013;110:220-226.

4 Zhou SK, Zhang J, Sa YL, Jin SB, Xu $\mathrm{YM}, \mathrm{Fu} \mathrm{Q}$, et al: Etiology and management of male iatrogenic urethral stricture: retrospective analysis of 172 cases in a single medical center. Urol Int 2016;97:386391.
5 Wein AJ, Kavoussi LR, Partin AW, Peters CA: Campbell-Walsh Urology 11th Edition. Philadelphia, Elsevier, 2016.

6 Moher D, Schulz KF, Altman DG: The CONSORT statement: revised recommendations for improving the quality of reports of parallel-group randomised trials. Lancet 2001;357:1191-1194.

7 Atak M, Tokgöz H, Akduman B, Erol B, Dönmez I, Hanc1 V, et al: Low-power holmium:YAG laser urethrotomy for urethral stricture disease: comparison of outcomes with the cold-knife technique. Kaohsiung J Med Sci 2011;27:503-507.

8 Jain SK, Kaza RC, Singh BK: Evaluation of holmium laser versus cold knife in optical internal urethrotomy for the management of short segment urethral stricture. Urol Ann 2014;6:328-333.

9 Jabłonowski Z, Kedzierski R, et al: Comparison of neodymium-doped yttrium aluminum garnet laser treatment with cold knife endoscopic incision of urethral strictures in male patients. Photomed Laser Surg 2010;28:239-244.

10 Dutkiewicz SA, Wroblewski M: Comparison of treatment results between holmium laser endourethrotomy and optical internal urethrotomy for urethral stricture. Int Urol Nephrol 2012;44:717-724.

11 Gallegos MA, Santucci RA: Advances in urethral stricture management. F1000Res 2016; 5:2913. 
12 Xue JD, Xie H, Fu Q, Feng C, Guo H, Xu YM: Single-staged improved tubularized preputial/penile skin flap urethroplasty for obliterated anterior urethral stricture: long-term results. Urol Int 2016;96:231-237.

13 Bullock TL, Brandes SB: Adult anterior urethral strictures: a national practice patterns survey of board certified urologists in the United States. J Urol 2007;177:685-690.

14 Carreño G, Patiño G, Perez J: Estado de la urología reconstructiva en Colombia: Tendencias en el tratamiento de la estrechez uretral anterior, una encuesta nacional. Congr SCU, 2016.
15 Buckley JC, Heyns C, Gilling P, Carney J: SIU/ ICUD consultation on urethral strictures: dilation, internal urethrotomy, and stenting of male anterior urethral strictures. Urology 2014;83(3 suppl):S18-S22.

16 Ogbonna BC: Managing many patients with a urethral stricture: a cost-benefit analysis of treatment options. Br J Urol 1998;81:741744 .

17 Greenwell TJ, Castle C, Andrich DE, MacDonald JT, Nicol DL, Mundy AR: Repeat urethrotomy and dilation for the treatment of urethral stricture are neither clinically effective nor cost-effective. J Urol 2004;172: 275-277.
18 Jin T, Li H, Jiang LH, Wang L, Wang KJ: Safety and efficacy of laser and cold knife urethrotomy for urethral stricture. Chin Med J (Engl) 2010;123:1589-1595.

19 Wessells H, Angermeier KW, Elliott S, Gonzalez CM, Kodama R, Peterson AC, et al: Male urethral stricture: American urological association guideline. J Urol 2017;197: 182-190.

20 Vicente J, Salvador J, Caffaratti J: Endoscopic urethrotomy versus urethrotomy plus $\mathrm{Nd}$ YAG laser in the treatment of urethral stricture. Eur Urol 1990;18:166-168. 